\title{
Correction
}

\section{Migration Status, Familial Risk for Mental Disorder, and Schizotypal Personality Traits}

Odin van der Stelt, Dounia Boubakri, Max Feltzer

\section{Note}

Please note that in the Results, the two group means given in the main text for the fourth statement on perceived discrimination should be $M=2.3$ and $M=1.5$ (as correctly reported in Table A4), not $M=3.3$ and $M=2.5$. 


\title{
Research Reports
}

\section{Migration Status, Familial Risk for Mental Disorder, and Schizotypal Personality Traits}

\author{
Odin van der Stelt ${ }^{* a}$, Dounia Boubakri ${ }^{a}$, Max Feltzer ${ }^{a}$ \\ [a] Department of Developmental and Clinical Psychology, Tilburg University, Tilburg, The Netherlands.
}

\begin{abstract}
Markedly raised incidence rates of schizophrenia and other psychotic disorders have been observed in several migrant and ethnic minority groups. To contribute to a better understanding of the elevated risk for psychotic disorders that is conferred by migration status, the present study examined effects associated with migration risk status on schizotypal personality traits, which are thought to reflect an underlying vulnerability to psychotic disorder. Effects of migration status were also compared to effects associated with a family history of psychopathology, which represents a robust nonspecific risk factor. We assessed schizotypal traits, using the Schizotypal Personality Questionnaire (SPQ), in a community-based sample of 62 Moroccan migrants and 41 Dutch nonmigrants, who were classified by the presence or absence of a family history of psychopathology. Overall, Moroccan migrants obtained higher SPQ scores than Dutch nonmigrants. However, migrants who had been classified as having a familial load of psychopathology displayed higher SPQ scores than migrants without such a family history, who in turn did not differ from Dutch nonmigrants. Furthermore, migrants with a familial load, relative to migrants without such a family history, reported higher levels of substance use and feelings of anxiety or depression, and perceived more often ethnic discrimination, which closely paralleled their SPQ scores. These findings indicate that primarily those migrants who are both intrinsically vulnerable and chronically exposed to social adversity, particularly ethnic discrimination, are at elevated risk for psychotic and other disorders. The results add to the evidence that migration status and perceived discrimination are associated with mental health.
\end{abstract}

Keywords: mental health, schizophrenia, psychotic disorders, ethnic minority, high-risk, individual differences, perceived discrimination

Europe's Journal of Psychology, 2013, Vol. 9(3), 552-571, doi:10.5964/ejop.v9i3.623

Received: 2013-05-03. Accepted: 2013-06-26. Published (VoR): 2013-08-30.

*Corresponding author at: Science \& Education, P.O. Box 92035, 1090 AA Amsterdam, The Netherlands. E-mail: ovdstelt@gmail.com

This is an open access article distributed under the terms of the Creative Commons Attribution License

(http://creativecommons.org/licenses/by/3.0), which permits unrestricted use, distribution, and reproduction in any medium, provided the original work is properly cited.

Schizophrenia is believed to be mediated largely by genetic risk factors, but environmental risk factors also have a critical role to play in its etiology (Ayalew et al., 2012; Harrison \& Weinberger, 2005; McGrath \& Murray, 2011; O'Donovan, Craddock, \& Owen, 2009). One factor that has received much scientific interest is migration or ethnic minority status. ${ }^{1}$ Markedly raised incidence rates of schizophrenia and other psychotic disorders have been observed in several migrant groups, as compared to "native" nonmigrant groups, in various countries, including the USA (Bresnahan et al., 2007; Cowan, Weber, Fisher, Bedno, \& Niebuhr, 2011; Ødegaard, 1932), the United Kingdom (Coid et al., 2008; Fearon et al., 2006), Denmark (Cantor-Graae, Pedersen, McNeil, \& Mortensen, 2003), and the Netherlands (Selten et al., 2001; Selten, Laan, Kupka, Smeets, \& van Os, 2012; Veling, Selten, Mackenbach, \& Hoek, 2007; Veling, Selten, Susser, Laan, Mackenbach, \& Hoek, 2007). According to a meta-analysis of 18 incidence studies of schizophrenia and other psychotic disorders (Cantor-Graae \& Selten, 2005), the risk ratio for migrants, as compared to the risk for native nonmigrant populations, is approximately 2.9. Another meta-analysis of incidence rates in England over a sixty-year period (1950-2009) reported similar risk ratios for several ethnic minority groups, with the highest risk ratio of 5.6 found for black Caribbean migrants (Kirkbride et al., 2012). 
The overall risk for psychotic disorders conferred by migration status is substantially larger than the risks associated to date with most other postulated environmental factors (e.g., prenatal exposure to infection or nutritional deficiencies, winter/spring birth, obstetric complications, substance use) (Cannon et al., 2003; Jones \& Tarrant, 2000; Kirkbride et al., 2012; McGrath \& Murray, 2011; Weiser, Davidson, \& Noy, 2005) and genetic factors (e.g., neuregulin 1, NRG1; catechol-O-methyltransferase, COMT) (Ayalew et al., 2012; Harrison \& Weinberger, 2005; O'Donovan et al., 2009). Consequently, the elevated rates of psychotic disorders observed in many migrant populations constitute a major public health problem. However, this issue remains contentious and has, so far, not received much attention from the general public, policy makers, and health care professionals (Morgan \& Hutchinson, 2010).

Several possible explanations have been suggested for the elevated rates of psychotic disorder observed in migrant and ethnic minority populations (Morgan, Charalambides, Hutchinson, \& Murray, 2010; Ødegaard, 1932; Selten \& Cantor-Graae, 2005; Sharpley, Hutchinson, Murray, \& McKenzie, 2001). These explanations include elevated rates of psychotic disorders in the birth country, selective migration of pre-psychotic individuals, disproportionate referral to services, cultural-diagnostic bias or misdiagnosis, and increased frequencies of putative risk factors, such as pregnancy or birth complications, urban living, or substance use. However, none of these explanations, alone or in combination, can fully account for the findings (Morgan et al., 2010; Selten \& Cantor-Graae, 2005; Sharpley et al., 2001).

A more plausible explanation could be that socio-environmental factors, in particular chronic exposure to adverse social environments, including social disadvantage, ethnic discrimination, and marginalization, mediate the relationship between migrant status and risk for psychotic illness (Collip, Myin-Germeys, \& van Os, 2008; Morgan et al., 2010; Morgan \& Hutchinson, 2010; Raine, 2006; Selten \& Cantor-Graae, 2005; Sharpley et al., 2001). This interpretation is supported by a meta-analysis (Cantor-Graae \& Selten, 2005), reporting that the risk for psychotic disorders is highest among migrant groups either from developing or non-Western countries or from countries where the population is predominantly black. Furthermore, ethnic discrimination experienced by members of migrant groups has been linked to an increased risk for both psychotic and mood disorders (Noh \& Kaspar, 2003; Veling, Selten, Susser, et al., 2007), as well as to a greater severity of psychotic symptoms (e.g., paranoid ideation) and affective symptoms (e.g., anxiety, depression) (Berg et al., 2011).

Accordingly, it has been hypothesized that migrants' chronic exposure to social adversity and environmental stress, also conceptualized as social defeat (Selten \& Cantor-Graae, 2005), facilitates a cognitive "paranoid" processing bias (Garety, Kuipers, Fowler, Freeman, \& Bebbington, 2001), especially in genetically vulnerable individuals and in combination with substance use. The chronic exposure to environmental stress operating upon an already biologically and cognitively vulnerable individual is thought to induce a "sensitization" of mesolimbic dopamine neurotransmission (Lieberman, Sheitman, \& Kinon, 1997), thereby increasing risk for developing a fullblown psychotic episode (Collip et al., 2008; Selten \& Cantor-Graae, 2005). This conceptualization is consistent with vulnerability-stress models of psychotic disorder (Cannon et al., 2003; Lenzenweger, 2006; Meehl, 1962, 1990; Morgan et al., 2010; Raine, 2006; Tsuang, Stone, \& Faraone, 2002; Zubin \& Spring, 1977), and with the hypothesized involvement of gene-environment interactions and epigenetic mechanisms in schizophrenia and related phenotypes (Cannon et al., 2003; Petronis, Paterson, \& Kennedy, 1999; Rutter, Moffitt, \& Caspi, 2006; van Os \& Linscott, 2012; van Os, Rutten, \& Poulton, 2008). 
The observed association between migration status and psychotic disorder is robust and relatively strong, but the underlying mechanisms through which migration status confers elevated risk for psychotic disorder remain poorly understood (Collip et al., 2008; Morgan et al., 2010; Rutter et al., 2006). Accordingly, in an effort to contribute to a better understanding of the increased risk that is associated with migration status, the present study examined individual differences in schizotypal personality traits in a community-based sample of Moroccan migrants and Dutch nonmigrants. Schizotypal traits refer to relatively stable personality characteristics that resemble, but represent attenuated forms of, the clinical symptoms of schizophrenia, such as altered perceptions, paranoid ideation, odd beliefs, and restricted affect. It is believed that individual differences in schizotypal personality traits reflect differences in the latent, unexpressed genetic or biological vulnerability to schizophrenia (Lenzenweger, 2006; Meehl, 1962, 1990; Raine, 1991, 2006; Tsuang et al., 2002; van Os \& Linscott, 2012; Zubin \& Spring, 1977). Therefore, we sought to determine, first, whether Moroccan migrants, who are at increased risk for psychotic disorders, as well as for mood disorders (Selten et al., 2001, 2012; Veling, Selten, Mackenbach, et al., 2007; Veling, Selten, Susser, et al., 2007), would show elevated, more pathological levels of schizotypal traits as compared to a Dutch nonmigrant group.

Moreover, we examined the effects associated with migration risk status in relation to the effects conferred by a family history of a psychiatric or substance use disorder, which has a significant relationship to psychotic disorder (Arendt, Mortensen, Rosenberg, Pedersen, \& Waltoft, 2008; Mortensen, Pedersen, \& Pedersen, 2010; van Os \& Linscott, 2012), and represents a robust risk factor for psychopathology in general (McLaughlin et al., 2012; van der Stelt, 1999). In line with vulnerability-stress models of schizophrenia (Cannon et al., 2003; Lenzenweger, 2006; Meehl, 1962, 1990; Morgan et al., 2010; Raine, 2006; Tsuang et al., 2002; Zubin \& Spring, 1977), we hypothesized that those Moroccan migrants who have a pre-existing familial load of psychopathology are at highest risk and, hence, would manifest the highest levels of schizotypal traits.

Furthermore, we evaluated the hypothesis that increased perceptions of ethnic discrimination among the Moroccan migrants would co-occur with higher levels of schizotypal traits, in light of the reported associations between perceived discrimination and clinically diagnosed psychotic and mood symptoms and disorders (Berg et al., 2011; Noh \& Kaspar, 2003; Veling, Selten, Susser, et al., 2007). Finally, we examined the separate and combined effects associated with migration risk status and family history risk status on levels of substance use and feelings of anxiety or depression, which also have been linked to psychotic and mood disorders (Ayalew et al., 2012; Cannon et al., 2003; Garety et al., 2001; Jones \& Tarrant, 2000; McGrath \& Murray, 2011; Sharpley et al., 2001; van Os \& Linscott, 2012). The present study should contribute to a better understanding of the association between migration status and risk for mental disorder, so that this information may contribute to future risk assessment, early intervention, and public health policy.

\section{Method}

\section{Participants}

Study participants consisted of a community-based sample of 62 Moroccan migrants and 41 Dutch nonmigrants (Table 1). Moroccan migrant status was assigned to persons with parents who were both born in Morocco and who have migrated to the Netherlands. ${ }^{2}$ The migrant group included 8 "first-generation" migrants, who were born in Morocco, and 54 "second-generation" migrants, who were born in the Netherlands. Dutch nonmigrant status was assigned to individuals who were born, as were both of their parents, in the Netherlands. Individuals who reported on a questionnaire to have one or more family members with a psychiatric or substance use disorder, 
hereafter referred to as psychopathology, were classified as having a "positive" family history of psychopathology (FHP). Individuals who reported to have no family members with psychopathology were classified as having a "negative" family history of psychopathology (FHN). Accordingly, each participant was classified as belonging to one of four groups defined by migration status (Moroccan migrant or Dutch nonmigrant) and FH (FHP or FHN) (Table 1).

Table 1

Age and Gender of Study Participants as a Function of Migration Status and Family History $(N=103)$

\begin{tabular}{|c|c|c|c|c|}
\hline & \multicolumn{2}{|c|}{ Moroccan migrant ( $n=62)$} & \multicolumn{2}{|c|}{ Dutch nonmigrant ( $n=41)$} \\
\hline & FHP $(n=24)$ & FHN $(n=38)$ & FHP $(n=17)$ & FHN $(n=24)$ \\
\hline Age (years) & $26.3_{a} \pm 4.8[18-37]$ & $23.5_{b} \pm 3.7[18-33]$ & $25.9_{\mathrm{ab}} \pm 6.5[18-40]$ & $28.3_{a} \pm 6.4[21-38]$ \\
\hline Male, $n$ & $11(46 \%)_{a}$ & $19(50 \%)_{a}$ & $5(29 \%)_{a}$ & $11(46 \%)_{a}$ \\
\hline Female, $n$ & $13(54 \%)_{\mathrm{a}}$ & $19(50 \%)_{a}$ & $12(71 \%)_{\mathrm{a}}$ & $13(54 \%)_{\mathrm{a}}$ \\
\hline \multicolumn{5}{|c|}{$\begin{array}{l}\text { Note. Data are given as mean } \pm S D \text { [min, max], unless where indicated otherwise. FH = family history of psychopathology dichotomized as } \\
\text { present or positive (FHP) and absent or negative (FHN). Migration status and family history are not significantly associated, as assessed by } \\
\text { a chi-square test of independence. Group means in the same row that share a letter in their subscripts do not differ significantly from each } \\
\text { other, as assessed by independent-samples } t \text { tests and chi-square tests. Holm's sequential Bonferroni procedure was used to control for Type } \\
\text { I error across the six pairwise group comparisons at the } .05 \text { level (two-tailed) of significance. }\end{array}$} \\
\hline
\end{tabular}

Participants were recruited individually over a period of several months (2011-2012) in a few larger cities located in the southern parts of the Netherlands. They were recruited from public areas, high schools, community colleges, club houses, and mosques by the second author (D. B.), who was highly familiar with the language, culture, and religion of the Moroccan community, an ethnic minority population which is usually difficult to reach. The second author recruited the participants and collected the data as a partial fulfillment of the requirements for a master's degree in psychology at Tilburg University. There were no exclusion criteria, except that participants had to be younger than 40 years of age and to possess sufficient proficiency of the Dutch language to understand and fill out the questionnaires. All participants were community volunteers, who did not receive any compensation for their participation.

\section{Materials and Procedure}

Migration Status and Family History of Psychopathology - Each participant was asked to fill out a questionnaire, which typically took no longer than 30 minutes to complete. The questionnaire was constructed by adapting and modifying the health questionnaire used by one of us in previous research (van der Stelt, 1999). The questionnaire included questions about the person's age, gender, date of birth, birth place, birth places of mother and father, and the occurrence of psychiatric or substance use disorders among his or her family members. Considerable care was taken to assure each participant that his or her answers will be kept strictly confidential, absolutely not shared with third parties, and only be used for scientific purposes in aggregate form, omitting any identifiable information. The study was approved by institutional review. Written informed consent was obtained from each participant. As described in the prior section, these data were utilized to classify the participants by migration status and FH (Table 1).

Schizotypal Personality Traits - A Dutch translation of the full-length Schizotypal Personality Questionnaire (SPQ) (Raine, 1991; Vollema \& Hoijtink, 2000), involving a self-report 74-item questionnaire with a dichotomous response format (yes/no), was utilized to assess schizotypal personality traits. Each "yes" response on the SPQ 
scores one point, so that the total raw score can range from 0 to 74 . The SPQ is a self-report multidimensional measure of schizotypy, which was developed not only as a clinical tool to assist in the diagnosis of schizotypal personality disorder, but also as a screening or research tool for the detection of subclinical pathology or the evaluation of inter-individual differences in schizotypal traits in the general population. The reliability and validity of the SPQ have been well-established (Calkins, Curtis, Grove, \& lacono, 2004; Raine, 1991; Vollema, Sitskoorn, Appels, \& Kahn, 2002). The SPQ consists of nine subscales (Tables A1 and A2). Factor analytic studies have demonstrated that the SPQ can be subdivided, in both community and clinical samples, into three distinct factors (Calkins et al., 2004; Raine, 1991, 2006; Raine, Reynolds, Lencz, Scerbo, Triphon, \& Kim, 1994; Vollema \& Hoijtink, 2000; Vollema et al., 2002), referred to as: (1) Cognitive-Perceptual Deficits (SPQ1), related to the "positive" clinical symptoms of schizophrenia (e.g., delusions, hallucinations); (2) Interpersonal Deficits (SPQ2), close to the "negative" symptoms (e.g., blunted affect, lack of motivation) and social impairment; and (3) Disorganized (SPQ3), related to the disintegration of thinking and behavior in schizophrenia (e.g., disorganized speech, bizarre behaviors). Measures of these three factors of schizotypy were derived by summation of the subscale raw scores for the relevant factors. In addition to the nine subscale scores and three factor scores, a total SPQ score was computed by summation of all the raw scores.

Substance Use, Feelings of Anxiety or Depression, and Perceived Discrimination — The questionnaire also contained questions asking to provide information, using a 4-point Likert-type response scale ("never", "sometimes", "often", "always"), about the participants' frequencies of: (a) use of alcohol (beer, wine, or other alcohol-containing drinks); (b) tobacco smoking; (c) use of cannabis (marijuana or hashish); (d) use of hard drugs (e.g., heroine, cocaine, amphetamines/speed/pep, XTC, or hallucinogenics); and (e) feelings of anxiety or depression in daily life. For Moroccan migrants, four questions were also included asking to indicate the degree to which he or she agrees or disagrees, on a 5-point Likert scale ("strongly disagree", "disagree", "neither agree nor disagree", "agree", "strongly agree"), with the following statements about feelings and experiences of ethnic discrimination, hereafter termed perceived discrimination, (1) "I do not feel accepted by native Dutch", (2) "I have been bullied or insulted due to my ethnic background", (3) "I have been threatened or attacked due to my ethnic background", and (4) "I feel others have behaved in an unfair or negative way toward my own ethnic group".

In addition to using the raw data distributions, the responses were scaled to obtain quantitative measures, using a scale of 1 to 4 for the data on substance use and feelings of anxiety or depression, and a scale of 0 to 4 for the data on perceived discrimination. Additionally, both the three scores obtained for substance (excluding alcohol) use and the four scores obtained for perceived discrimination were summed to derive measures of the overall levels of substance use and perceived discrimination. Also, the percentages of users of each class of substance in each group were employed as dependent variables. Note that we anticipated that the number of hard drug users among the participants would be small, as use of these substances is uncommon in the general population, and that alcohol use among the Moroccan migrants, almost all of whom would describe themselves as Muslim (The Netherlands Institute for Social Research, 2005), would be limited due to cultural and religious factors.

\section{Statistical Analysis}

To assess the separate and combined effects of migration status and FH on the SPQ measures, we conducted a two-way univariate analysis of variance (ANOVA), including migrant status (Moroccan migrant and Dutch nonmigrant) and FH (FHP and FHN) as between-subjects factors. Pairwise group comparisons on the SPQ and categorical (nominal and ordinal) data were performed using one-way ANOVAs, Pearson chi-square $\left(\mathrm{X}^{2}\right)$ tests or Fisher Exact tests, and Mann-Whitney $U$ tests. For Moroccan migrants, the Pearson product-moment correlation 
coefficient $(r)$ was computed to examine the relations between the overall measure of perceived discrimination and the SPQ measures. Holm's sequential Bonferroni procedure was used to control for Type I error across the six pairwise group comparisons at the .05 level (two-tailed) of significance.

Although we are fully aware of the interpretative difficulties that may arise when ordinal data are converted to interval data, it seems reasonable to endorse a pragmatic orientation to the relation between level of measurement and type of statistical analysis (Pedhazur \& Pedhazur-Schmelkin, 1991). Correspondingly, we believe that the parametric tests on the ordinal data are useful here because: (a) they provide additional information about the direction of the average answer; (b) the underlying scale and measured variable can be thought of as if continuous; and (c) they enable the assessment of interactions between factors, as well as allowing statistical control of other, potential confounding variables, particularly age.

Preliminary data inspection showed that significant age-related differences existed among the groups (Table 1) and that age exerted a modest, though significant, effect on the SPQ and substance use measures. Therefore, we took possible age-related effects on between-group differences into account by entering age as a covariate in the ANOVA and by partialling age-related effects out from the computed Pearson $r$. As statistical control of "nuisance" or potential confounding variables is by no means trivial (Meehl, 1970; Pedhazur, 1997), we present the results on both the raw, uncorrected data and the age-adjusted data, as recommended (Simmons, Nelson, \& Simonsohn, 2011).

\section{Results}

\section{Schizotypal Personality Traits}

Significant main effects of FH were observed for the total SPQ score, SPQ1 (Cognitive-Perceptual Deficits) factor score, and SPQ2 (Interpersonal Deficits) factor score (Tables 2 and 3), reflecting that participants who had been classified as FHP, averaged across both migrant groups, displayed higher scores than participants who were classified as FHN (e.g., Total SPQ score: $M=20.2, S D=11.6$ vs. $M=11.6, S D=9.4$ ). A significant main effect of migration status was also found for the SPQ2 (Interpersonal Deficits) factor score (Table 3), reflecting that Moroccan migrants, averaged across both FH groups, showed a higher SPQ2 factor score than did the Dutch nonmigrants $(M=8.4, S D=5.6$ vs. $M=5.5, S D=5.2)$ (Table 2$)$.

Table 2

Schizotypal Personality Questionnaire Scores as a Function of Migration Status and Family History $(N=103)$

\begin{tabular}{lccccc}
\hline & \multicolumn{2}{c}{ Moroccan migrant $(\boldsymbol{n}=\mathbf{6 2})$} & & \multicolumn{2}{c}{ Dutch nonmigrant $(\boldsymbol{n}=\mathbf{4 1})$} \\
\cline { 2 - 3 } Dependent variable & FHP $(\boldsymbol{n}=\mathbf{2 4})$ & FHN $(\boldsymbol{n}=\mathbf{3 8})$ & & FHP $(\boldsymbol{n}=\mathbf{1 7})$ & FHN $(\boldsymbol{n}=\mathbf{2 4})$ \\
\hline Total SPQ (raw score) & $23.3_{\mathrm{a}} \pm 11.7[2-48]$ & $12.2_{\mathrm{b}} \pm 10.8[1-52]$ & & $15.8_{\mathrm{b}} \pm 10.2[4-44]$ & $10.7_{\mathrm{b}} \pm 6.5[0-28]$ \\
SPQ1: Cognitive-Perceptual Deficits (factor score) & $11.2_{\mathrm{a}} \pm 5.9[1-23]$ & $5.1_{\mathrm{b}} \pm 5.1[0-23]$ & & $7.6_{\mathrm{ab}} \pm 4.8[2-17]$ & $5.3_{\mathrm{b}} \pm 3.7[0-12]$ \\
SPQ2: Interpersonal Deficits (factor score) & $10.8_{\mathrm{a}} \pm 5.3[0-19]$ & $7.0_{\mathrm{b}} \pm 5.3[0-25]$ & & $7.3_{\mathrm{ab}} \pm 6.5[1-24]$ & $4.2_{\mathrm{b}} \pm 3.8[0-16]$ \\
SPQ3: Disorganized (factor score) & $5.0_{\mathrm{a}} \pm 4.0[0-14]$ & $2.2_{\mathrm{b}} \pm 2.9[0-14]$ & & $2.5_{\mathrm{ab}} \pm 2.8[1-14]$ & $2.77_{\mathrm{ab}} \pm 2.7[0-13]$ \\
\hline
\end{tabular}

Note. Data are given as mean $\pm S D$ [min, max]. FH = family history of psychopathology dichotomized as present or positive (FHP) and absent or negative $(\mathrm{FHN}) . \mathrm{SPQ}=$ Schizotypal Personality Questionnaire. Group means in the same row that share a letter in their subscripts do not differ significantly from each other, as assessed by pairwise comparisons using one-way ANOVAs and one-way ANCOVAs including age as a covariate. Holm's sequential Bonferroni procedure was used to control for Type I error across the six pairwise group comparisons at the .05 level (two-tailed) of significance. 
Table 3

Results of Statistical Analyses of Migration Status and Family History on Schizotypal Personality Questionnaire Scores (N = 103)

\begin{tabular}{|c|c|c|c|c|c|c|c|}
\hline \multirow[b]{2}{*}{ Dependent variable } & \multirow[b]{2}{*}{ Effect } & \multicolumn{3}{|c|}{ ANOVA } & \multicolumn{3}{|c|}{ ANCOVA } \\
\hline & & $F(1,99)$ & $p$ & $n_{p}^{2}$ & $F(1,98)$ & $p$ & $n_{p}^{2}$ \\
\hline \multirow[t]{3}{*}{ Total SPQ (raw score) } & M & 4.68 & .033 & .045 & 3.44 & .067 & .034 \\
\hline & $\mathrm{FH}$ & 15.25 & $<.001$ & .133 & 15.57 & $<.001$ & .137 \\
\hline & $\mathrm{M} \times \mathrm{FH}$ & 2.01 & .159 & .020 & 2.89 & .093 & .029 \\
\hline \multirow[t]{3}{*}{ SPQ1 (factor score) } & $M$ & 2.78 & .099 & .027 & 2.59 & .110 & .026 \\
\hline & $\mathrm{FH}$ & 16.98 & $<.001$ & .146 & 16.81 & $<.001$ & .146 \\
\hline & $\mathrm{M} \times \mathrm{FH}$ & 3.36 & .070 & .033 & 3.19 & .077 & .031 \\
\hline \multirow[t]{3}{*}{ SPQ2 (factor score) } & M & 8.68 & .004 & .081 & 6.33 & .013 & .061 \\
\hline & $\mathrm{FH}$ & 10.70 & .001 & .098 & 11.29 & .001 & .103 \\
\hline & $\mathrm{M} \times \mathrm{FH}$ & 0.11 & .737 & .001 & 0.66 & .418 & .007 \\
\hline \multirow[t]{3}{*}{ SPQ3 (factor score) } & M & 2.29 & .134 & .023 & 1.51 & .222 & .015 \\
\hline & $\mathrm{FH}$ & 4.20 & .043 & .041 & 4.33 & .040 & .042 \\
\hline & $\mathrm{M} \times \mathrm{FH}$ & 5.42 & .022 & .052 & 6.58 & .012 & .063 \\
\hline
\end{tabular}

Note. Statistical analyses involve two-way (migration status and family history of psychopathology) univariate analyses of variance (ANOVAs) and covariance (ANCOVAs) including age as a covariate. SPQ = Schizotypal Personality Questionnaire. SPQ1 = SPQ Factor 1 (CognitivePerceptual Deficits). SPQ2 = SPQ Factor 2 (Interpersonal Deficits). SPQ3 = SPQ Factor 3 (Disorganized). $\mathrm{M}=$ migration status. $\mathrm{FH}=$ family history of psychopathology. $\mathrm{M} \times \mathrm{FH}=$ two-way interaction between $\mathrm{M}$ and $\mathrm{FH}$.

Additionally, a significant FH main effect was seen for the SPQ3 (Disorganized) factor score, along with a significant two-way interaction with migration status (Table 3). The interaction reflects that Moroccan migrants who were classified as FHP manifested a higher SPQ3 score than did Moroccan migrants who were considered FHN (Table 2). As indexed by the effect size estimate $\left(\eta_{p}{ }^{2}\right), \mathrm{FH}$ made a greater independent contribution to the total variance in the SPQ measures (from about $4 \%$ of SPQ3 variance to 15\% of SPQ1 variance) than did migration status (from about $3 \%$ of SPQ1 variance to $6 \%$ of SPQ2 variance), irrespective of the exclusion or inclusion of age as a covariate (Table 3).

Table 4

Results of Statistical Analyses of Family History on Schizotypal Personality Questionnaire Scores for Moroccan Migrants ( $n=62$ )

\begin{tabular}{|c|c|c|c|c|c|c|c|c|}
\hline \multirow[b]{2}{*}{ Dependent variable } & \multicolumn{4}{|c|}{ ANOVA } & \multicolumn{4}{|c|}{ ANCOVA } \\
\hline & $F(1,60)$ & $p$ & $95 \% \mathrm{Cl}$ & $n_{p}^{2}$ & $F(1,59)$ & $p$ & $95 \% \mathrm{Cl}$ & $n_{p}^{2}$ \\
\hline Total SPQ (raw score) & 14.40 & $<.001$ & {$[5.2-16.9]$} & .194 & 14.42 & $<.001$ & {$[5.5-17.9]$} & .196 \\
\hline SPQ1 (factor score) & 18.48 & $<.001$ & [3.3-8.9] & .235 & 17.68 & $<.001$ & [3.3-9.3] & .231 \\
\hline SPQ2 (factor score) & 7.79 & .007 & {$[1.1-6.6]$} & .115 & 9.67 & .003 & {$[1.6-7.4]$} & .141 \\
\hline SPQ3 (factor score) & 10.27 & .002 & {$[1.1-4.6]$} & .146 & 8.99 & .004 & {$[0.9-4.7]$} & .132 \\
\hline
\end{tabular}

Note. Statistical analyses involve one-way (family history of psychopathology) univariate analyses of variance (ANOVAs) and covariance (ANCOVAs) including age as a covariate. SPQ = Schizotypal Personality Questionnaire. SPQ1 = SPQ Factor 1 (Cognitive-Perceptual Deficits). SPQ2 = SPQ Factor 2 (Interpersonal Deficits). SPQ3 = SPQ Factor 3 (Disorganized). Cl = confidence interval for mean difference [lower bound, upper bound].

Pairwise comparisons support the aforementioned results, but also indicate that in particular the Moroccan migrants who were classified as FHP displayed significantly higher scores, not only on the SPQ3, but on all SPQ measures when compared directly to the Moroccan migrants who were considered FHN (Table 4), who in turn did not differ 
markedly from the Dutch nonmigrant groups (Table 2). Similarly, at the SPQ subscale level (Tables A1 and A2), $\mathrm{FH}$ main effects were found for most of the subscales, whereas effects of migration status (except for the main effect on No Close Friends) were significant only in interaction with $\mathrm{FH}$ and were restricted to the Odd/Eccentric Behavior, Odd Speech, and Suspiciousness subscales. Correspondingly, elevated scores on these subscales were seen only among Moroccan migrants who were classified as FHP (Table A1).

\section{Substance Use}

As anticipated, the percentage of alcohol users among Moroccan migrants was significantly lower than seen among Dutch nonmigrants ( $21 \%$ vs. $88 \%$; Tables 5 and A3). Moroccan migrants also reported to use alcohol less frequently than Dutch nonmigrants. No significant overall differences in the percentage of alcohol users, or in the frequency of alcohol use, were found as a function of $\mathrm{FH}$.

The percentages of tobacco smokers, cannabis users, and substance users in general did not vary significantly as a function of migration status or family history (Tables 5 and A3). Only 6 participants reported to use "sometimes" hard drugs, which precluded statistical group comparisons. Yet, it is noteworthy that Moroccan migrants who were classified as FHP included the highest proportion of hard drug users (Table 5).

Moreover, Moroccan migrants with a FHP tended to include higher percentages of users of alcohol and cannabis, as well as reporting to smoke tobacco more often, than did the Moroccan migrants with a FHN (Table 5). However, these FH-related differences approached ( $p$ s ranging from .023 to .057), though did not exceed, strict Bonferroniadjusted levels of significance and, for tobacco smoking, became no longer significant when age-related effects were taken into account (Table A3).

Nonetheless, a significant two-way interaction effect was detected on the overall level of substance use, irrespective of age (Table A3). Moroccan migrants who had been classified as FHP reported to use substances significantly more often as compared to Moroccan migrants who were classified as $\mathrm{FHN}, F(1,60)=11.63, p=.001, \eta_{p}{ }^{2}=$ $.162 ; F(1,59)=7.59, p=.008, \eta_{p}{ }^{2}=.114$, who in turn did not differ from the Dutch nonmigrant groups (Table 5).

To assess whether the observed FH-related group differences among the Moroccan migrants in the overall level of substance use contributed to the differences between these groups in the SPQ measures, we carried out an additional ANCOVA, including both age and the overall level of substance use as covariates. It was found that the differences between the FHP and FHN migrant groups in the SPQ measures became smaller, yet remained large and significant after group differences in age and the overall level of substance use were taken into account (e.g., Total SPQ score: $F(1,58)=9.06, p=.004, \eta_{p}{ }^{2}=.135$ ).

\section{Feelings of Anxiety or Depression}

No significant overall differences were found as a function of migration status, but individuals who were considered FHP reported, across migrant groups, a higher frequency of feelings of anxiety or depression than did individuals with a FHN (Tables 5 and A3). Also, Moroccan migrants who had been classified as a FHP reported to experience feelings of anxiety or depression more often than did Moroccan migrants with a FHN, but they did not differ significantly from the Dutch nonmigrant groups (Table 5).

\section{Perceived Discrimination}

Moroccan migrants who were classified as FHP reported a higher overall level of agreement with the four statements on ethnic discrimination than did the Moroccan migrants classified as FHN (Table A4), in particular in relation to 
Table 5

Substance Use and Feelings of Anxiety or Depression as a Function of Migration Status and Family History $(N=103)$

\begin{tabular}{|c|c|c|c|c|}
\hline \multirow[b]{2}{*}{ Dependent variable } & \multicolumn{2}{|c|}{ Moroccan migrant $(n=62)$} & \multicolumn{2}{|c|}{ Dutch nonmigrant $(n=41)$} \\
\hline & FHP $(n=24)$ & FHN $(n=38)$ & $\operatorname{FHP}(n=17)$ & FHN $(n=24)$ \\
\hline Alcohol users, $n$ & $8(33 \%)_{a}$ & $5(13 \%)_{a}$ & $15(88 \%)_{b}$ & $21(88 \%)_{b}$ \\
\hline \multicolumn{5}{|l|}{ Frequency of use } \\
\hline Median [min, max] & $1[1,4]$ & $1[1,3]$ & $2[1,3]$ & $2[1,3]$ \\
\hline Mean rank & \multicolumn{2}{|c|}{$38_{a}$} & \multicolumn{2}{|c|}{$74_{b}$} \\
\hline Mean rank & $35 a$ & $29 a$ & $21_{b}$ & $21_{b}$ \\
\hline Response average $(S D)$ & $1.5_{a}(0.8)$ & $1.2_{a}(0.4)$ & $2.3_{b}(0.7)$ & $2.3_{b}(0.7)$ \\
\hline Tobacco smokers, $n$ & $9(38 \%)_{a}$ & $4(11 \%)_{a}$ & $4(24 \%)_{a}$ & $7(29 \%)_{a}$ \\
\hline \multicolumn{5}{|l|}{ Frequency of use } \\
\hline Median [min, max] & $1[1,4]$ & $1[1,4]$ & $1[1,3]$ & $1[1,3]$ \\
\hline Mean rank & \multicolumn{2}{|c|}{$51_{a}$} & \multicolumn{2}{|c|}{$54 \mathrm{a}$} \\
\hline Mean rank & 37 a & $28_{b}$ & $20 a$ & $22 \mathrm{a}$ \\
\hline Response average $(S D)$ & $1.8_{\mathrm{a}}(1.1)$ & $1.2^{\mathrm{a}}{ }_{\mathrm{ab}}(0.5)$ & $1.4_{\mathrm{ab}}(0.8)$ & $1.5_{a b}(1.0)$ \\
\hline Cannabis users, $n$ & $6(25 \%)_{a}$ & $2(5 \%)_{a}$ & $3(18 \%)_{a}$ & $4(17 \%)_{a}$ \\
\hline \multicolumn{5}{|l|}{ Frequency of use } \\
\hline Median [min, max] & $1[1,4]$ & $1[1,2]$ & $1[1,3]$ & $1[1,3]$ \\
\hline Mean rank & \multicolumn{2}{|c|}{$51_{\mathrm{a}}$} & \multicolumn{2}{|c|}{$54 a$} \\
\hline Mean rank & $35 a$ & 29 a & $21 a$ & $21 \mathrm{a}$ \\
\hline Response average $(S D)$ & $1.4_{a}(0.8)$ & $1.1_{\mathrm{a}}(0.2)$ & $1.3_{a}(0.7)$ & $1.3_{a}(0.6)$ \\
\hline Hard drug users, ${ }^{b} n$ & $4(17 \%)$ & $0(0 \%)$ & $1(6 \%)$ & $1(4 \%)$ \\
\hline Substance users, ${ }^{c} n$ & $10(42 \%)_{a}$ & $6(16 \%)_{a}$ & $4(24 \%)_{a}$ & $6(25 \%)_{a}$ \\
\hline \multicolumn{5}{|l|}{ Frequency of use } \\
\hline Median [min, max] & $3[3,10]$ & $3[3,6]$ & $3[3,8]$ & $3[3,7]$ \\
\hline Mean rank & \multicolumn{2}{|c|}{$50 a$} & \multicolumn{2}{|c|}{$55_{a}$} \\
\hline Mean rank & $37_{a}$ & $28_{b}$ & 20 a & 22 a \\
\hline Response average $(S D)$ & $4.3_{a}(1.9)$ & $3.2_{b}(0.6)$ & $3.8_{\mathrm{ab}}(1.5)$ & $3.8_{a b}(1.2)$ \\
\hline \multicolumn{5}{|c|}{ Frequency of feelings of anxiety or depression } \\
\hline Median [min, max] & $1.5[1,2]$ & $1[1,2]$ & $2[1,2]$ & $1[1,2]$ \\
\hline Mean rank & \multicolumn{2}{|c|}{$49 a$} & \multicolumn{2}{|c|}{57 a } \\
\hline Mean rank & $39_{a}$ & $27_{b}$ & $25 a$ & $19 a_{a}$ \\
\hline Response average $(S D)$ & $1.5_{a}(0.5)$ & $1.1_{b}(0.3)$ & $1.6_{a}(0.5)$ & $1.3_{\mathrm{ab}}(0.5)$ \\
\hline
\end{tabular}

Note. FH = family history of psychopathology dichotomized as present or positive (FHP) and absent or negative (FHN). Data values in the same row that share a letter in their subscripts do not differ significantly from each other, as assessed by Pearson chi-square tests, MannWhitney $U$ tests, or one-way ANOVAs and one-way ANCOVAs including age as a covariate. Response categories are scaled as: never $=1$, sometimes $=2$, often $=3$, always $=4$. Mean rank values in the upper rows are derived from one Mann-Whitney $U$ test assessing the effect, across both FH groups, associated with migration status; mean ranks in the lower rows are derived from two Mann-Whitney $U$ tests assessing the effect, separately for Moroccan migrants and Dutch nonmigrants, associated with FH. Holm's sequential Bonferroni procedure was used to control for Type I error across the pairwise group comparisons at the .05 level (two-tailed) of significance.

${ }^{a}$ Bold subscript at the response average value of tobacco smoking indicates the result of the one-way ANCOVA with age as a covariate. ${ }^{b}$ Hard drugs refer to heroine, cocaine, amphetamines/speed/pep, XTC, or hallucinogenics. The limited number of participants who reported to use these drugs precluded formal pairwise comparisons.

'Substance users refer to individuals who reported to smoke tobacco, use cannabis and/or use hard drugs.

the fourth statement (mean rank: 38 vs. 27 , Mann-Whitney $U=290, z=2.49, p=.013 ; M=3.3, S D=1.1$ vs. $M$ $\left.=2.5, S D=1.3, F(1,60)=6.12, p=.016, n_{p}^{2}=.093 ; F(1,59)=4.53, p=.037, \eta_{p}^{2}=.071\right)$; the data in relation to the first three statements did not differ significantly as a function of $\mathrm{FH}$ (Table A4). These findings indicate that 
migrants with a FHP reported, as compared to migrants with a FHN, to perceive more often ethnic discrimination, particularly discrimination against members of their own ethnic group in general, as opposed to direct personal experiences of ethnic discrimination.

Significant correlations were seen in the data from the Moroccan migrants who were classified as FHP between the overall measure of perceived discrimination and the total SPQ score, $r(22)=.507, p=.011, \operatorname{pr}(21)=.506, p$ $=.014, \mathrm{SPQ} 1$ factor score, $r(22)=.445, p=.029, \operatorname{pr}(21)=.445, p=.033$, SPQ2 factor score, $r(22)=.461, p=$ $.023, \operatorname{pr}(21)=.470, p=.024$, and SPQ3 factor score, $r(22)=.482, p=.017, \operatorname{pr}(21)=.488, p=.018$, such that higher levels of perceived discrimination were associated with higher SPQ scores (Figure 1). No significant (partial) correlations ( $p s>.267$ ) were observed in the data from the Moroccan migrants who were considered FHN.

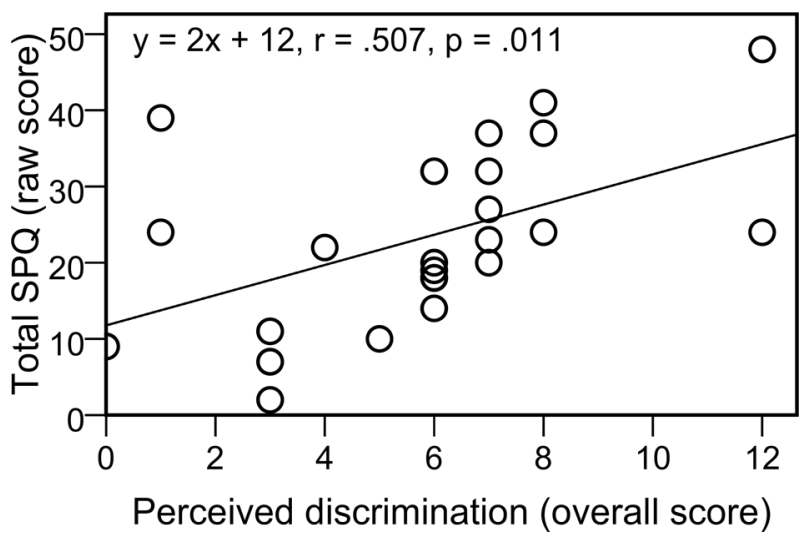

Figure 1. Scatter plot and least-squares regression line relating the overall scores of perceived discrimination to the total Schizotypy Personality Questionnaire (SPQ) scores observed among Moroccan migrants who had been classified by the presence of a family history of psychopathology $(n=24)$.

\section{Discussion}

As a group, Moroccan migrants were found to display a higher Interpersonal Deficits (SPQ2) factor score than did the Dutch nonmigrants, whereas no significant overall group differences were observed in the scores on the total SPQ, Cognitive-Perceptual Deficits (SPQ1), and Disorganized (SPQ3) factor. To our knowledge, these results are new, and support the hypothesis that higher levels of schizotypal traits, especially those related to social-interpersonal impairment, are prominent personality characteristics among Moroccan migrants, which potentially contribute to the markedly raised risk for psychotic and mood disorders observed in this ethnic minority population in the Netherlands (Selten et al., 2001, 2012; Veling, Selten, Mackenbach, et al., 2007; Veling, Selten, Susser, et al., 2007).

This conclusion, however, should be qualified because not all individuals within the Moroccan migrant group showed elevated Interpersonal Deficits scores, but primarily those migrants who had been classified as having a family history of a psychiatric or substance use disorder. These findings underline that Moroccan migrants cannot be considered as a homogenous group, but that great heterogeneity exists within one ethnic minority group. Moreover, Moroccan migrants who were characterized by a pre-existing familial load of psychopathology manifested substantially higher scores on the total SPQ, Cognitive-Perceptual Deficits, and Disorganized factor. Similarly, they reported higher levels of substance use and feelings of anxiety or depression than did the Moroccan migrants 
without such a family history, who in turn did not differ markedly (except in alcohol use) from the Dutch nonmigrant groups.

Furthermore, Moroccan migrants with a familial load reported, as compared to Moroccan migrants without such a family history, to perceive more often ethnic discrimination, which closely paralleled, in a dose-related manner, their SPQ scores. The latter finding bears a strong resemblance to the reported associations between perceived discrimination and psychotic and mood symptoms and disorders (Berg et al., 2011; Noh \& Kaspar, 2003; Veling, Selten, Susser, et al., 2007). The present findings are in line with vulnerability-stress models of psychotic disorder (Cannon et al., 2003; Collip et al., 2008; Lenzenweger, 2006; Meehl, 1962, 1990; Morgan et al., 2010; Raine, 2006; Tsuang et al., 2002; Zubin \& Spring, 1977). The results support our hypothesis that primarily those Moroccan migrants who have a pre-existing familial load, along with relatively high levels of substance use and feelings of anxiety or depression, and enhanced perceptions of ethnic discrimination, are most vulnerable (and/or most susceptible to adverse environments, see Rutter et al., 2006; van Os et al., 2008) and exhibit the highest levels of schizotypal traits.

It seems even plausible to assume that a small number of Moroccan migrants who exhibited the highest SPQ scores fulfilled already, at study entry, formal clinical diagnostic criteria for schizotypal personality disorder (SPD), given that highly elevated SPQ scores in community samples have a well-established relationship to SPD (Raine, 1991, 2006). Alternatively, the Moroccan migrants who had a familial load and who displayed the highest SPQ scores were functioning in the pre-onset or prodromal stage of illness. This stage is characterized by subclinical and nonspecific symptoms, or an "ultra-high risk" mental state, which herald the onset of a full-blown clinical psychotic or depressive episode (McGorry, Killackey, \& Yung, 2008; van der Stelt, Lieberman, \& Belger, 2005; van Os \& Linscott, 2012). However, as the present study employed a cross-sectional design, longitudinal followup data are required to examine the latter hypothesis.

Family history was associated with generalized and moderate-to-strong effects on the SPQ measures, whereas migration status was associated with relatively specific and small-to-moderate effects. Furthermore, family history and migration status made independent contributions to the variance in the Interpersonal Deficits scores, indicating that the effects of these two variables on this factor of schizotypy are mediated by partially distinct mechanisms. Family history, but not migration status, showed a significant association, not only with the level of anxiety or depression experienced in daily life, but also with the Cognitive-Perceptual Deficits factor, which has been linked specifically to the latent, unexpressed genetic vulnerability to schizophrenia (Vollema et al., 2002; but see Raine, 2006).

It may be hypothesized, then, that the effects conferred by family history are largely mediated by familial-genetic factors, which may affect all SPQ factors, yet may be most closely linked to Cognitive-Perceptual Deficits, along with effects on risk for psychopathology in general. By contrast, the effects conferred by migration status may be determined primarily by socio-environmental factors, which may be reflected most strongly by Interpersonal Deficits. Additionally, the interaction effects between family history and migration status may be manifested specifically in the Disorganized factor. This interpretation seems compatible with the distinction between two postulated clinical subtypes, namely "neurodevelopmental schizotypy" which is mediated mainly by genetic and early biologic risk factors and is linked to schizophrenia, and "pseudo-schizotypy" which originates primarily from later psychosocial adversity (Raine, 2006). In a similar vein, it has been hypothesized that there exists both a neurodevelopmental pathway and a sociodevelopmental pathway to psychotic disorder (Morgan et al., 2010). Thus, it is conceivable 
that a familial-genetic vulnerability and the chronic exposure to adverse social environments, particularly ethnic discrimination, together with substance use, all contribute, in both a simple additive and an interactive synergetic fashion (van Os et al., 2008), to the markedly higher levels of schizotypal traits seen among the Moroccan migrants with a family history of psychopathology.

The present study has several strengths and limitations that require consideration. Initially, a strategic advantage is that we utilized the "high-risk" design and examined community volunteers, and not clinically diagnosed patients. It is unlikely, therefore, that the obtained results are confounded by treatment, hospitalization, acute psychosis or other factors related to clinically expressed psychiatric illness (Lenzenweger, 2006; Raine, 2006; van der Stelt, 1999; van der Stelt et al., 2005). Similarly, we evaluated only migrants from Morocco, and not migrants from other non-Western countries (e.g., Suriname, Turkey), which facilitates statistical conclusion validity, yet may limit external validity. Indeed, differences in incidence rates of psychotic disorder observed between migrant groups (Coid et al., 2008; Fearon et al., 2006; Kirkbride et al., 2012; Selten et al., 2012; Veling, Selten, Mackenbach, et al., 2007; Veling, Selten, Susser, et al., 2007) have been related to the operation of additional risk factors (e.g., pregnancy or birth complications, disrupted family structure) or protective factors (e.g., socio-ethnic support, ethnic group identity) that are specific for a given migrant population (Kirkbride et al., 2012; Morgan et al., 2010). Alternatively, migrant groups with the highest rates of psychotic disorder may have been exposed to comparatively greater social adversity and higher levels of ethnic discrimination, which actually apply to first- and second-generation Moroccan migrants who live in present-day Dutch society (The Netherlands Institute for Social Research, 2005; Roes 2008; Veling, Selten, Susser, et al., 2007). In any case, it is difficult to assess the external validity of the present results; additional research is required to determine whether the findings generalize to the Moroccan migrant population as a whole and whether they generalize to other migrant groups.

Additionally, we employed a nonexperimental design, which cannot definitely exclude potential bias or confounding (Meehl, 1970; Pedhazur, 1997). Literacy, cultural or ethnic-specific factors, however, do not seem to have confounded the results because enhanced levels of SPQ scores were found mainly among the Moroccan migrants with a family history of psychopathology, and not among the Moroccan migrants without such a family history. Also, most participants were born in larger cities and the four groups did not differ by season of birth, making it unlikely that these postulated risk factors acted as confounding variables. Despite these observations, in nonexperimental research it is difficult to identify and rule out all potential confounding or "nuisance" variables (e.g., prenatal adversity, birth complications, urban living, impaired family environment) other than the independent variables as possible alternative explanations for observed results, particularly in the absence of a theoretical and conceptual framework that specifies the nature (e.g., exogenous vs. endogenous, mediator vs. moderator), magnitude, and direction of the relationships among all variables involved (Meehl, 1970; Pedhazur, 1997). Accordingly, one should be cautious when interpreting the present findings until they have been replicated, refined, or refuted.

Another potential study limitation is that we collected all the data through self-report questionnaires instead of interviews. A more thorough assessment using a personal interview could have provided more accurate and detailed information. However, it has been shown that a multidimensional paper-and-pencil self-report measure as the $\mathrm{SPQ}$ is reliable and valid to characterize schizotypal features in community and clinical samples (Calkins et al., 2004; Raine, 1991, 2006; Raine et al., 1994; Vollema \& Hoijtink, 2000; Vollema et al., 2002). Yet, the self-report measure of substance use may have underestimated the extent of substance use among the participants. However, we emphasized the confidentiality of the obtained data and, relative to a direct interview, a self-report questionnaire 
offers participants a stronger feeling of anonymity (Evans \& Rooney, 2008). Furthermore, the attitude towards substance use is fairly liberal and tolerant in the Netherlands. This and our emphasis on the protection of privacy make it unlikely that the answers given by the participants are confounded by social desirability. Even if social desirability or some other kind of response bias did occur, this may not have affected the observed between-group differences as long as there is no differential misreporting between the four groups.

Additionally, our self-report measure of family history risk status was not focused on a diagnostically specific psychiatric or substance use disorder, but on psychopathology in general. The reasons behind this choice were that a family history of psychopathology holds significance for psychotic illness (Arendt et al., 2008; Mortensen et al., 2010; van Os \& Linscott, 2012), and represents a robust nonspecific risk factor (McLaughlin et al., 2012; van der Stelt, 1999). Another reason was related to practical limitations and the fact that we should have examined substantial larger sample sizes if we had focused solely on a family history of psychotic disorder because such a family history is uncommon in the general population. Similarly, from a public health perspective, there may be more widespread benefits involved to identify risk factors for psychopathology in general because the base rates are substantially higher in the general population (Jones \& Tarrant, 2000; Weiser et al., 2005). Nonetheless, an important goal for future research is to determine whether the effects associated with migration status and family history on schizotypal traits as reported herein are different in nature or magnitude when diagnostically more specific disorders are assessed among family members.

These study limitations notwithstanding, we observed that Moroccan migrants, primarily those with a familial load of psychopathology, display highly elevated levels of schizotypal traits. Moreover, higher levels of schizotypal traits seen among Moroccan migrants with a familial load paralleled their enhanced perceptions of ethnic discrimination, along with higher levels of substance use and feelings of anxiety or depression. We hypothesize that all these risk factors may contribute to the markedly raised incidence rates of psychotic and mood disorders found in this ethnic minority population in the Netherlands (Selten et al., 2001, 2012; Veling, Selten, Mackenbach, et al., 2007; Veling, Selten, Susser, et al., 2007). More broadly, the present results add to the evidence that migration status and perceived discrimination are associated with mental health.

\section{Acknowledgement}

The authors are grateful to Meinte G. Vollema, PhD, for providing us with the Dutch translation of the SPQ, and to Laurentz Dekkers, MSc, for performing a pilot study.

\section{Notes}

1) The term migrants is used in this text in a broad sense to refer to individuals who belong to migrant, immigrant and/or ethnic minority groups.

2) In the Netherlands, the proportions of non-Western migrant or ethnic minority groups have substantially increased during the past 40 years, from $1-2 \%$ of the general population to more than $10 \%$ (Roes, 2008). The largest migrant groups, each consisting of slightly more than $2 \%$ of the general population, originate from Turkey, Morocco, and Suriname, and live mainly in the larger cities in the more "deprived" neighborhoods (The Netherlands Institute for Social Research, 2005; Roes, 2008).

\section{References}

Arendt, M., Mortensen, P. B., Rosenberg, R., Pedersen, C. B., \& Waltoft, B. L. (2008). Familial predisposition for psychiatric disorder: Comparison of subjects treated for cannabis-induced psychosis and schizophrenia. Archives of General Psychiatry, 65(11), 1269-1274. doi:10.1001/archpsyc.65.11.1269 
Ayalew, M., Le-Niculescu, H., Levey, D. F., Jain, N., Changala, B., Patel, S. D., . . Niculescu, A. B. (2012). Convergent functional genomics of schizophrenia: From comprehensive understanding to genetic risk prediction. Molecular Psychiatry, 17(9), 887-905. doi:10.1038/mp.2012.37

Berg, A. O., Melle, I., Rossberg, J. I., Romm, K. L., Larsson, S., Lagerberg, T. V., . . Hauff, E. (2011). Perceived discrimination is associated with severity of positive and depression/anxiety symptoms in immigrants with psychosis: A cross-sectional study. BMC Psychiatry, 11, Article 77. doi:10.1186/1471-244X-11-77

Bresnahan, M., Begg, M. D., Brown, A., Schaefer, C., Sohler, N., Insel, B., . . Susser, E. (2007). Race and risk of schizophrenia in a US birth cohort: Another example of health disparity? International Journal of Epidemiology, 36(4), 751-758. doi:10.1093/ije/dym041

Calkins, M. E., Curtis, C. E., Grove, W. M., \& lacono, W. G. (2004). Multiple dimensions of schizotypy in first degree biological relatives of schizophrenia patients. Schizophrenia Bulletin, 30(2), 317-325. doi:10.1093/oxfordjournals.schbul.a007081

Cannon, T. D., van Erp, T. G., Bearden, C. E., Loewy, R., Thompson, P., Toga, A. W., ... Tsuang, M. T. (2003). Early and late neurodevelopmental influences in the prodrome to schizophrenia: Contributions of genes, environment, and their interactions. Schizophrenia Bulletin, 29(4), 653-669. doi:10.1093/oxfordjournals.schbul.a007037

Cantor-Graae, E., Pedersen, C. B., McNeil, T. F., \& Mortensen, P. B. (2003). Migration as a risk factor for schizophrenia: A Danish population-based cohort study. The British Journal of Psychiatry, 182, 117-122. doi:10.1192/bjp.182.2.117

Cantor-Graae, E., \& Selten, J. P. (2005). Schizophrenia and migration: A meta-analysis and review. The American Journal of Psychiatry, 162(1), 12-24. doi:10.1176/appi.ajp.162.1.12

Coid, J. W., Kirkbride, J. B., Barker, D., Cowden, F., Stamps, R., Yang, M., \& Jones, P. B. (2008). Raised incidence rates of all psychoses among migrant groups: Findings from the East London first episode psychosis study. Archives of General Psychiatry, 65(11), 1250-1258. doi:10.1001/archpsyc.65.11.1250

Collip, D., Myin-Germeys, I., \& van Os, J. (2008). Does the concept of "sensitization" provide a plausible mechanism for the putative link between the environment and schizophrenia? Schizophrenia Bulletin, 34(2), 220-225. doi:10.1093/schbul/sbm163

Cowan, D. N., Weber, N. S., Fisher, J. A., Bedno, S. A., \& Niebuhr, D. W. (2011). Incidence of adult onset schizophrenic disorders in the US military: Patterns by sex, race and age. Schizophrenia Research, 127(1-3), 235-240. doi:10.1016/j.schres.2010.12.005

Evans, A. N., \& Rooney, B. J. (2008). Methods in psychological research. Los Angeles, CA: Sage Publications.

Fearon, P., Kirkbride, J. B., Morgan, C., Dazzan, P., Morgan, K., Lloyd, T., . . Murray, R. M. (2006). Incidence of schizophrenia and other psychoses in ethnic minority groups: Results from the MRC AESOP study. Psychological Medicine, 36(11), 1541-1550. doi:10.1017/S0033291706008774

Garety, P. A., Kuipers, E., Fowler, D., Freeman, D., \& Bebbington, P. E. (2001). A cognitive model of the positive symptoms of psychosis. Psychological Medicine, 31(2), 189-195. doi:10.1017/S0033291701003312

Harrison, P. J., \& Weinberger, D. R. (2005). Schizophrenia genes, gene expression, and neuropathology: On the matter of their convergence. Molecular Psychiatry, 10(1), 40-68. doi:10.1038/sj.mp.4001558

Europe's Journal of Psychology 
Jones, P. B., \& Tarrant, C. J. (2000). Developmental precursors and biological markers for schizophrenia and affective disorders: Specificity and public health implications. European Archives of Psychiatry and Clinical Neuroscience, $250(6), 286-291$. doi: $10.1007 / \mathrm{s} 004060070003$

Kirkbride, J. B., Errazuriz, A., Croudace, T. J., Morgan, C., Jackson, D., Boydell, J., . . . Jones, P. B. (2012). Incidence of schizophrenia and other psychoses in England, 1950-2009: A systematic review and meta-analyses. PLoS ONE, 7(3), e31660. doi:10.1371/journal.pone.0031660

Lenzenweger, M. F. (2006). Schizotypy: An organizing framework for schizophrenia research. Current Directions in Psychological Science, 15(4), 162-166. doi:10.1111/j.1467-8721.2006.00428.x

Lieberman, J. A., Sheitman, B. B., \& Kinon, B. J. (1997). Neurochemical sensitization in the pathophysiology of schizophrenia: Deficits and dysfunction in neuronal regulation and plasticity. Neuropsychopharmacology, 17(4), $205-229$. doi:10.1016/S0893-133X(97)00045-6

McGorry, P. D., Killackey, E., \& Yung, A. (2008). Early intervention in psychosis: Concepts, evidence and future directions. World Psychiatry; Official Journal of the World Psychiatric Association (WPA), 7(3), 148-156. doi:10.1002/j.2051-5545.2008.tb00182.x

McGrath, J. J., \& Murray, R. M. (2011). Environmental risk factors for schizophrenia. In D. R. Weinberger \& P. J. Harrison (Eds.), Schizophrenia (3rd ed., pp. 226-244). Oxford, UK: Wiley-Blackwell. doi:http://dx.doi.org/10.1002/9781444327298.ch11

McLaughlin, K. A., Gadermann, A. M., Hwang, I., Sampson, N. A., Al-Hamzawi, A., Andrade, L. H., . . Kessler, R. C. (2012). Parent psychopathology and offspring mental disorders: Results from the WHO World Mental Health Surveys. The British Journal of Psychiatry, 200(4), 290-299. doi:10.1192/bjp.bp.111.101253

Meehl, P. E. (1962). Schizotaxia, schizotypy, schizophrenia. The American Psychologist, 17, 827-838. doi:10.1037/h0041029

Meehl, P. E. (1970). Nuisance variables and the ex post facto design. In M. Radner \& S. Winokur (Eds.), Minnesota Studies in the Philosophy of Science: Vol. 4. Analyses of theories and methods of physics and psychology (pp. 373-402). Minneapolis, MN: University of Minneapolis Press.

Meehl, P. E. (1990). Toward an integrated theory of schizotaxia, schizotypy and schizophrenia. Journal of Personality Disorders, 4(1), 1-99. doi:10.1521/pedi.1990.4.1.1

Morgan, C., Charalambides, M., Hutchinson, G., \& Murray, R. M. (2010). Migration, ethnicity, and psychosis: Toward a sociodevelopmental model. Schizophrenia Bulletin, 36(4), 655-664. doi:10.1093/schbul/sbq051

Morgan, C., \& Hutchinson, G. (2010). The social determinants of psychosis in migrant and ethnic minority populations: A public health tragedy. Psychological Medicine, 40(5), 705-709. doi:10.1017/S0033291709005546

Mortensen, P. B., Pedersen, M. G., \& Pedersen, C. B. (2010). Psychiatric family history and schizophrenia risk in Denmark: Which mental disorders are relevant? Psychological Medicine, 40(2), 201-210. doi:10.1017/S0033291709990419

The Netherlands Institute for Social Research (SCP/WODC/CBS). (2005). Jaarrapport Integratie 2005 [Annual report on integration 2005]. The Hague, The Netherlands: Author.

Noh, S., \& Kaspar, V. (2003). Perceived discrimination and depression: Moderating effects of coping, acculturation, and ethnic support. American Journal of Public Health, 93(2), 232-238. doi:10.2105/AJPH.93.2.232 
Ødegaard, Ø. (1932). Emigration and insanity. Acta Psychiatrica et Neurologica, 7, (Suppl. 4), 1-206. doi:10.1097/00005053-193312000-00060

O'Donovan, M. C., Craddock, N. J., \& Owen, M. J. (2009). Genetics of psychosis: Insights from views across the genome. Human Genetics, 126(1), 3-12. doi:10.1007/s00439-009-0703-0

Pedhazur, E. J. (1997). Multiple regression in behavioral research: Explanation and prediction (3rd ed.). Belmont, CA: Wadsworth.

Pedhazur, E. J., \& Pedhazur-Schmelkin, L. (1991). Measurement, design, and analysis: An integrated approach. New York, NY: Psychology Press.

Petronis, A., Paterson, A. D., \& Kennedy, J. L. (1999). Schizophrenia: An epigenetic puzzle? Schizophrenia Bulletin, 25(4), 639-655. doi:10.1093/oxfordjournals.schbul.a033408

Raine, A. (1991). The SPQ: A scale for the assessment of schizotypal personality based on DSM-III-R criteria. Schizophrenia Bulletin, 17(4), 555-564. doi:10.1093/schbul/17.4.555

Raine, A. (2006). Schizotypal personality: Neurodevelopmental and psychosocial trajectories. Annual Review of Clinical Psychology, 2, 291-326. doi:10.1146/annurev.clinpsy.2.022305.095318

Raine, A., Reynolds, C., Lencz, T., Scerbo, A., Triphon, N., \& Kim, D. (1994). Cognitive-perceptual, interpersonal, and disorganized features of schizotypal personality. Schizophrenia Bulletin, 20(1), 191-202. doi:10.1093/schbul/20.1.191

Roes, T. (Ed.). (2008). Facts and figures of the Netherlands: Social and cultural trends 1995-2006. The Hague, The Netherlands: The Netherlands Institute for Social Research. Retrieved from http://www.scp.nl/english/Publications/Publications_by_year/Publications_2008/Facts_and_Figures_of_the_Netherlands

Rutter, M., Moffitt, T. E., \& Caspi, A. (2006). Gene-environment interplay and psychopathology: Multiple varieties but real effects. Journal of Child Psychology and Psychiatry, and Allied Disciplines, 47(3-4), 226-261. doi:10.1111/j.1469-7610.2005.01557.x

Selten, J. P., \& Cantor-Graae, E. (2005). Social defeat: Risk factor for schizophrenia? The British Journal of Psychiatry, 187, 101-102. doi:10.1192/bjp.187.2.101

Selten, J. P., Laan, W., Kupka, R., Smeets, H. M., \& van Os, J. (2012). Risk of psychiatric treatment for mood disorders and psychotic disorders among migrants and Dutch nationals in Utrecht, The Netherlands. Social Psychiatry and Psychiatric Epidemiology, 47(2), 271-278. doi:10.1007/s00127-010-0335-7

Selten, J. P., Veen, N., Feller, W., Blom, J. D., Schols, D., Camoenië, W., . . Kahn, R. (2001). Incidence of psychotic disorders in immigrant groups to the Netherlands. The British Journal of Psychiatry, 178, 367-372. doi:10.1192/bjp.178.4.367

Sharpley, M. S., Hutchinson, G., Murray, R. M., \& McKenzie, K. (2001). Understanding the excess of psychosis among the African-Caribbean population in England: Review of current hypotheses. The British Journal of Psychiatry, 178(40), s60-s68. doi:10.1192/bjp.178.40.s60

Simmons, J. P., Nelson, L. D., \& Simonsohn, U. (2011). False-positive psychology: Undisclosed flexibility in data collection and analysis allows presenting anything as significant. Psychological Science, 22(11), 1359-1366. doi:10.1177/0956797611417632 
Tsuang, M. T., Stone, W. S., \& Faraone, S. V. (2002). Understanding predisposition to schizophrenia: Toward intervention and prevention. Canadian Journal of Psychiatry, 47(6), 518-526.

van Os, J., \& Linscott, R. J. (2012). Introduction: The extended psychosis phenotype-relationship with schizophrenia and with ultrahigh risk status for psychosis. Schizophrenia Bulletin, 38, 227-230. doi:10.1093/schbul/sbr188

van Os, J., Rutten, B. P. F., \& Poulton, R. (2008). Gene - Environment interactions in schizophrenia: Review of epidemiological findings and future directions. Schizophrenia Bulletin, 34(6), 1066-1082. doi:10.1093/schbul/sbn117

van der Stelt, O. (1999). Visual P3 as a potential vulnerability marker of alcoholism: Evidence from the Amsterdam study of children of alcoholics. Alcohol and Alcoholism, 34(3), 267-282. doi:10.1093/alcalc/34.3.267

van der Stelt, O., Lieberman, J. A., \& Belger, A. (2005). Auditory P300 in high-risk, recent-onset and chronic schizophrenia. Schizophrenia Research, 77(2-3), 309-320. doi:10.1016/j.schres.2005.04.024

Veling, W., Selten, J. P., Mackenbach, J. P., \& Hoek, H. W. (2007). Symptoms at first contact for psychotic disorder: Comparison between native Dutch and ethnic minorities. Schizophrenia Research, 95(1-3), 30-38. doi:10.1016/j.schres.2007.06.024

Veling, W., Selten, J. P., Susser, E., Laan, W., Mackenbach, J. P., \& Hoek, H. W. (2007). Discrimination and the incidence of psychotic disorders among ethnic minorities in the Netherlands. International Journal of Epidemiology, 36(4), 761-768. doi:10.1093/ije/dym085

Vollema, M. G., \& Hoijtink, H. (2000). The multidimensionality of self-report schizotypy in a psychiatric population: An analysis using multidimensional Rasch models. Schizophrenia Bulletin, 26(3), 565-575. doi:10.1093/oxfordjournals.schbul.a033478

Vollema, M. G., Sitskoorn, M. M., Appels, M. C. M., \& Kahn, R. S. (2002). Does the schizotypal personality questionnaire reflect the biological-genetic vulnerability to schizophrenia? Schizophrenia Research, 54(1-2), 39-45.

doi:10.1016/S0920-9964(01)00350-4

Weiser, M., Davidson, M., \& Noy, S. (2005). Comments on risk for schizophrenia. Schizophrenia Research, 79(1), 15-21. doi:10.1016/j.schres.2005.05.005

Zubin, J., \& Spring, B. (1977). Vulnerability: A new view on schizophrenia. Journal of Abnormal Psychology, 86(2), 103-126. doi:10.1037/0021-843X.86.2.103 


\section{Appendix}

Table A1

Schizotypal Personality Questionnaire Subscale Scores as a Function of Migration Status and Family History $(N=103)$

\begin{tabular}{|c|c|c|c|c|}
\hline \multirow[b]{2}{*}{ SPQ subscale } & \multicolumn{2}{|c|}{ Moroccan migrant $(n=62)$} & \multicolumn{2}{|c|}{ Dutch nonmigrant $(n=41)$} \\
\hline & $\operatorname{FHP}(n=24)$ & FHN $(n=38)$ & FHP $(n=17)$ & FHN $(n=24)$ \\
\hline Ideas of reference & $4.2_{\mathrm{a}} \pm 2.5[0-8]$ & $2.2_{b} \pm 2.3[0-8]$ & $3.1 \mathrm{ab} \pm 2.2[0-7]$ & $2.3_{b} \pm 1.9[0-5]$ \\
\hline Excessive social anxiety & $2.2_{\mathrm{a}} \pm 1.7[0-6]$ & $1.2_{\mathrm{ab}} \pm 1.5[0-7]$ & $2.5 \mathrm{ac} \pm 2.7[0-8]$ & $1.0_{\mathrm{ac}} \pm 1.4[0-5]$ \\
\hline Odd beliefs or magical thinking & $1.3_{\mathrm{a}} \pm 1.5[0-4]$ & $0.2_{b} \pm 0.5[0-2]$ & $1.6_{\mathrm{a}} \pm 1.9[0-6]$ & $0.8_{a} \pm 1.2[0-4]$ \\
\hline Unusual perceptual experiences & $2.0_{a} \pm 1.9[0-7]$ & $0.6_{b} \pm 1.5[0-8]$ & $1.3_{\mathrm{ab}} \pm 1.5[0-4]$ & $0.7_{b} \pm 0.9[0-3]$ \\
\hline Odd or eccentric behavior & $1.5_{a} \pm 1.6[0-5]$ & $0.5_{\mathrm{ab}} \pm 1.0[0-5]$ & $0.5_{a b} \pm 1.2[0-4]$ & $0.6_{a b} \pm 1.1[0-5]$ \\
\hline No close friends & $3.2_{\mathrm{a}} \pm 1.8[0-6]$ & $2.5_{a} \pm 1.8[0-9]$ & $1.9_{\mathrm{ab}} \pm 2.3[0-8]$ & $1.0_{b} \pm 1.1[0-4]$ \\
\hline Odd speech & $3.5_{a} \pm 2.8[0-9]$ & $1.7_{\mathrm{a}} \pm 2.1[0-9]$ & $2.0_{a} \pm 2.0[0-8]$ & $2.1_{a} \pm 1.8[0-8]$ \\
\hline Constricted affect & $1.7_{\mathrm{a}} \pm 1.1[0-3]$ & $1.3_{\mathrm{ab}} \pm 1.4[0-6]$ & $1.2 \mathrm{ab} \pm 1.4[0-4]$ & $0.6_{b} \pm 1.0[0-4]$ \\
\hline Suspiciousness & $3.7_{\mathrm{a}} \pm 2.1[0-8]$ & $2.0_{b} \pm 1.9[0-7]$ & $1.6_{b} \pm 1.4[0-5]$ & $1.5_{b} \pm 1.3[0-4]$ \\
\hline
\end{tabular}

Note. Data are given as mean $\pm S D$ [min, max]. FH = family history of psychopathology dichotomized as present or positive (FHP) and absent or negative $(\mathrm{FHN}) . \mathrm{SPQ}=$ Schizotypal Personality Questionnaire. Group means in the same row that share a letter in their subscripts do not differ significantly from each other, as assessed by pairwise comparisons using one-way ANOVAs and one-way ANCOVAs including age as a covariate; for group means where the results of the ANOVA and ANCOVA differ from each other, an additional bold subscript indicates the result of the ANCOVA. Holm's sequential Bonferroni procedure was used to control for Type I error across the six pairwise group comparisons at the .05 level (two-tailed) of significance.

Table A2

Results of Statistical Analyses of Migration Status and Family History on Schizotypal Personality Questionnaire Subscale Scores (N = 103)

\begin{tabular}{|c|c|c|c|c|c|c|c|}
\hline \multirow[b]{2}{*}{ SPQ subscale } & \multirow[b]{2}{*}{ Effect } & \multicolumn{3}{|c|}{ ANOVA } & \multicolumn{3}{|c|}{ ANCOVA } \\
\hline & & $F(1,99)$ & $p$ & $n_{p}^{2}$ & $F(1,98)$ & $p$ & $\eta_{p}^{2}$ \\
\hline \multirow[t]{3}{*}{ Ideas of reference } & M & 1.12 & .293 & .011 & 0.87 & .355 & .009 \\
\hline & $\mathrm{FH}$ & 9.24 & .003 & .085 & 9.22 & .003 & .086 \\
\hline & $\mathrm{M} \times \mathrm{FH}$ & 1.52 & .220 & .015 & 1.72 & .193 & .017 \\
\hline \multirow[t]{3}{*}{ Excessive social anxiety } & M & 0.06 & .805 & .001 & 0.53 & .468 & .005 \\
\hline & $\mathrm{FH}$ & 12.08 & .001 & .109 & 12.97 & $<.001$ & .117 \\
\hline & $\mathrm{M} \times \mathrm{FH}$ & 0.41 & .523 & .004 & 0.01 & .944 & $<.001$ \\
\hline \multirow[t]{3}{*}{ Odd beliefs or magical thinking } & M & 3.18 & .078 & .031 & 1.84 & .178 & .018 \\
\hline & $\mathrm{FH}$ & 13.07 & $<.001$ & .117 & 13.17 & $<.001$ & .118 \\
\hline & $\mathrm{M} \times \mathrm{FH}$ & 0.36 & .550 & .004 & 0.01 & .919 & $<.001$ \\
\hline \multirow[t]{3}{*}{ Unusual perceptual experiences } & M & 1.16 & .284 & .012 & 0.97 & .327 & .010 \\
\hline & $\mathrm{FH}$ & 10.28 & .002 & .094 & 10.22 & .002 & .094 \\
\hline & $\mathrm{M} \times \mathrm{FH}$ & 1.42 & .237 & .014 & 1.50 & .223 & .015 \\
\hline \multirow[t]{3}{*}{ Odd or eccentric behavior } & M & 2.86 & .094 & .028 & 2.07 & .154 & .021 \\
\hline & $\mathrm{FH}$ & 4.10 & .046 & .040 & 4.19 & .043 & .041 \\
\hline & $\mathrm{M} \times \mathrm{FH}$ & 5.81 & .018 & .055 & 6.74 & .011 & .064 \\
\hline \multirow[t]{3}{*}{ No close friends } & M & 13.94 & $<.001$ & .123 & 11.60 & .001 & .106 \\
\hline & $\mathrm{FH}$ & 5.38 & .022 & .052 & 5.53 & .021 & .053 \\
\hline & $\mathrm{M} \times \mathrm{FH}$ & 0.04 & .847 & $<0.001$ & 0.01 & .909 & $<.001$ \\
\hline \multirow[t]{3}{*}{ Odd speech } & M & 1.48 & .227 & .015 & 0.91 & .344 & .009 \\
\hline & $\mathrm{FH}$ & 3.21 & .076 & .031 & 3.31 & .072 & .033 \\
\hline & $\mathrm{M} \times \mathrm{FH}$ & 3.90 & .051 & .038 & 4.85 & .030 & .047 \\
\hline
\end{tabular}

Europe's Journal of Psychology 


\begin{tabular}{|c|c|c|c|c|c|c|c|}
\hline \multirow[b]{2}{*}{ SPQ subscale } & \multirow[b]{2}{*}{ Effect } & \multicolumn{3}{|c|}{ ANOVA } & \multicolumn{3}{|c|}{ ANCOVA } \\
\hline & & $F(1,99)$ & $p$ & $\eta_{p}^{2}$ & $F(1,98)$ & $p$ & $n_{p}^{2}$ \\
\hline \multirow[t]{3}{*}{ Constricted affect } & M & 4.74 & .032 & .046 & 2.90 & .092 & .029 \\
\hline & $\mathrm{FH}$ & 3.48 & .065 & .034 & 3.81 & .054 & .037 \\
\hline & $\mathrm{M} \times \mathrm{FH}$ & 0.25 & .616 & $<.001$ & $<.001$ & .960 & $<.001$ \\
\hline \multirow[t]{3}{*}{ Suspiciousness } & $M$ & 13.83 & $<.001$ & .123 & 12.21 & .001 & .111 \\
\hline & $\mathrm{FH}$ & 6.60 & .012 & .062 & 6.63 & .012 & .063 \\
\hline & $\mathrm{M} \times \mathrm{FH}$ & 4.86 & .030 & .047 & 5.25 & .024 & .051 \\
\hline
\end{tabular}

Note. Statistical analyses involve two-way (migration status and family history of psychopathology) univariate analyses of variance (ANOVAs) and covariance (ANCOVAs) including age as a covariate. SPQ = Schizotypal Personality Questionnaire. $\mathrm{M}=$ migration status. $\mathrm{FH}=$ family history of psychopathology. $\mathrm{M} \times \mathrm{FH}=$ two-way interaction between $\mathrm{M}$ and $\mathrm{FH}$.

\section{Table A3}

Results of Statistical Analyses of Migration Status and Family History on Substance Use and Feelings of Anxiety or Depression ( $N=103)$

\begin{tabular}{|c|c|c|c|c|c|c|c|c|c|c|}
\hline \multirow[b]{2}{*}{ Dependent variable } & \multirow[b]{2}{*}{ Effect } & \multicolumn{3}{|c|}{ Mann-Whitney $U$ test } & \multicolumn{3}{|c|}{ ANOVA } & \multicolumn{3}{|c|}{ ANCOVA } \\
\hline & & $U / z$ & $p$ & $\mathbf{v}$ & $F(1,99)$ & $p$ & $\eta_{p}^{2}$ & $F(1,98)$ & $p$ & $n_{p}^{2}$ \\
\hline \multirow[t]{3}{*}{ Frequency of alcohol use } & M & $380 / 6.61$ & $<.001$ & .688 & 55.94 & $<.001$ & .361 & 57.27 & $<.001$ & .369 \\
\hline & $\mathrm{FH}$ & $1084 / 1.39$ & .166 & .176 & 1.79 & .184 & .018 & 1.86 & .176 & .029 \\
\hline & $\mathrm{M} \times \mathrm{FH}$ & NA & NA & NA & 0.99 & .322 & .010 & 1.55 & .217 & .016 \\
\hline \multirow[t]{3}{*}{ Frequency of tobacco smoking } & M & $1202 / 0.63$ & .527 & .076 & $<0.01$ & .991 & $<.001$ & 0.01 & .785 & .001 \\
\hline & $\mathrm{FH}$ & $1079 / 1.75$ & .080 & .336 & 1.99 & .162 & .020 & 1.93 & .169 & .019 \\
\hline & $\mathrm{M} \times \mathrm{FH}$ & NA & NA & NA & 4.56 & .035 & .044 & 3.51 & .084 & .030 \\
\hline \multirow[t]{3}{*}{ Frequency of cannabis use } & M & $1211 / 0.66$ & .510 & .203 & 0.25 & .616 & .003 & 0.63 & .431 & .006 \\
\hline & $\mathrm{FH}$ & $1111 / 1.76$ & .079 & .190 & 2.50 & .117 & .025 & 2.62 & .109 & .045 \\
\hline & $\mathrm{M} \times \mathrm{FH}$ & NA & NA & NA & 1.44 & .233 & .014 & 2.31 & .132 & .023 \\
\hline \multirow[t]{3}{*}{ Frequency of substance use ${ }^{a}$} & $M$ & $1145 / 1.05$ & .293 & .198 & 0.01 & .920 & $<.001$ & $<.01$ & .986 & $<.001$ \\
\hline & $\mathrm{FH}$ & $1077 / 1.61$ & .107 & .303 & 3.89 & .051 & .038 & 3.82 & .054 & .038 \\
\hline & $\mathrm{M} \times \mathrm{FH}$ & NA & NA & NA & 4.96 & .028 & .048 & 4.23 & .042 & .041 \\
\hline \multirow{3}{*}{$\begin{array}{l}\text { Frequency of feelings of anxiety or } \\
\text { depression }\end{array}$} & M & $1072 / 1.66$ & .097 & .164 & 2.37 & .126 & .023 & 2.70 & .104 & .027 \\
\hline & $\mathrm{FH}$ & $815 / 3.81$ & $<.001$ & .377 & 15.05 & $<.001$ & .132 & 15.07 & $<.001$ & .133 \\
\hline & $\mathrm{M} \times \mathrm{FH}$ & NA & NA & NA & 0.30 & .583 & .003 & 0.49 & .488 & .005 \\
\hline
\end{tabular}

Note. Statistical analyses involve Mann-Whitney $U$ tests to assess the overall effects of migration status and family history of psychopathology, and two-way (migration status and family history of psychopathology) univariate analyses of variance (ANOVAs) and covariance (ANCOVAs) including age as a covariate. $\mathrm{V}=$ Cramer's $\mathrm{V}$. $\mathrm{M}=$ migration status. $\mathrm{FH}=$ family history of psychopathology. $\mathrm{M} \times \mathrm{FH}=\mathrm{two}-\mathrm{way}$ interaction between $\mathrm{M}$ and $\mathrm{FH}$. NA = not applicable.

aSubstance use refers to tobacco smoking, cannabis use and/or use of hard drugs (e.g., heroine, cocaine, amphetamines/speed/pep, XTC, or hallucinogenics). 


\section{Table A4}

Perceived Discrimination as a Function of Family History

\begin{tabular}{|c|c|c|}
\hline \multirow[b]{2}{*}{ Item } & \multicolumn{2}{|c|}{ Moroccan migrants $(n=62)$} \\
\hline & FHP $(n=24)$ & FHN $(n=38)$ \\
\hline \multicolumn{3}{|c|}{ (a) I do not feel accepted by native Dutch } \\
\hline Median [min, max] & $1.5[0,3]$ & $1[0,4]$ \\
\hline Mean rank & $34 \mathrm{a}$ & $30 \mathrm{a}$ \\
\hline Response average $(S D)$ & $1.5_{a}(0.8)$ & $1.3_{\mathrm{a}}(1.0)$ \\
\hline \multicolumn{3}{|c|}{ (b) I have been bullied or insulted due to my ethnic background } \\
\hline Median [min, max] & $1[0,4]$ & $0.5[0,3]$ \\
\hline Mean rank & $34 \mathrm{a}$ & $30 \mathrm{a}$ \\
\hline Response average $(S D)$ & $1.1_{\mathrm{a}}(1.0)$ & $0.9_{a}(0.9)$ \\
\hline \multicolumn{3}{|c|}{ (c) I have been threatened or attacked due to my ethnic background } \\
\hline Median [min, max] & $2[0,3]$ & $1[0,3]$ \\
\hline Mean rank & $35 a$ & 29 a \\
\hline Response average $(S D)$ & $0.9_{\mathrm{a}}(0.8)$ & $0.6_{\mathrm{a}}(0.8)$ \\
\hline \multicolumn{3}{|c|}{ (d) I feel others have behaved in an unfair or negative way toward my own ethnic group } \\
\hline Median [min, max] & $3[0,4]$ & $2[0,4]$ \\
\hline Mean rank & $38_{a}$ & $27_{\mathrm{b}}$ \\
\hline Response average $(S D)$ & $2.3_{\mathrm{a}}(1.1)$ & $1.5_{\mathrm{b}}(1.3)$ \\
\hline \multicolumn{3}{|c|}{ Overall level of agreement $(a+b+c+d)$ (total score) } \\
\hline Median [min, max] & $6[0,12]$ & $5[0,10]$ \\
\hline Mean rank & 38 a & $28_{\mathrm{b}}$ \\
\hline Response average $(S D)$ & $5.8_{\mathrm{a}}(3.0)$ & $4.3_{a}(2.7)$ \\
\hline
\end{tabular}

Note. FH = family history of psychopathology dichotomized as present or positive (FHP) and absent or negative (FHN). Data values in the same row that share a letter in their subscripts do not differ significantly from each other, as assessed by Mann-Whitney $U$ tests, one-way ANOVAs and one-way ANCOVAs, including age as a covariate, at the .05 level (two-tailed) of significance. Response categories are scaled as: strongly disagree $=0$, disagree $=1$, neither agree nor disagree $=2$, agree $=3$, strongly agree $=4$. Mean rank values are derived from Mann-Whitney $U$ tests assessing the effect associated with $\mathrm{FH}$.

\section{About the Authors}

Odin van der Stelt, PhD, has extensive experience in teaching and research in the areas of psychology, psychiatry, addiction, and the clinical and cognitive neurosciences.

Dounia Boubakri, MSc, holds a master's degree in developmental and clinical psychology and has specific expertise in the area of cross-cultural psychology.

Max Feltzer, PhD, has extensive experience in teaching and research in the areas of developmental psychology, clinical psychology, health psychology, and neuropsychology. 